\title{
LONG-TERM FOLLOW-UP OF TRUNCUS ARTERIOSUS REPAIRED IN INFANCY: A TWENTY-YEAR EXPERIENCE
}

Hiranya A. Rajasinghe, MD Doff B. McElhinney, MS V. Mohan Reddy, MD

Bassem N. Mora, MD

Frank L. Hanley, MD
Background: There have been few reports of long-term follow-up after truncus arteriosus repair in infancy. Methods: A retrospective review was performed to assess long-term outcomes among 165 patients who survived the initial hospital stay after complete repair of truncus arteriosus since 1975. The median age at truncus repair over this 20 -year experience was 3.5 months (range 2 days to 36 years), and $81 \%$ of patients were less than 1 year of age. Previous pulmonary artery banding had been performed in 15 patients, and two patients had undergone prior repair of interrupted aortic arch. Significant procedures performed along with truncus repair included truncal valve replacement $(n=10)$ or repair $(n=5)$ and repair of interrupted aortic arch $(n=4)$. Results: Patients were followed up for up to 20.4 years (median 10.5 years). Twenty-five patients were lost at cross-sectional follow-up, with a total of 67 patient-years of follow-up available on these patients. There have been 23 late deaths, eight of which occurred within 6 months of repair and 13 of which occurred within 1 year. Ten of the late deaths were related to reoperations. Actuarial survival among all hospital survivors was $90 \%$ at 5 years, $85 \%$ at 10 years, and $83 \%$ at 15 years and was essentially identical for infants alone. A significant independent risk factor for poorer long-term survival was truncus with moderate to severe truncal valve insufficiency before repair. During the follow-up period, 107 patients underwent 133 conduit reoperations. Median time to conduit reoperation was 5.5 years, and the only factor significantly associated with shorter time to conduit replacement was smaller conduit size at initial repair. In addition, 26 patients underwent 30 truncal valve replacements. Six patients required truncal valve replacement before any conduit-related reintervention, with two associated deaths. Actuarial freedom from truncal valve replacement among patients with no prerepair truncal valve insufficiency was $95 \%$ at 10 years. Actuarial freedom from truncal valve replacement was significantly lower among patients with truncal insufficiency before initial repair (63\% at 10 years). At follow-up, all patients except three were in New York Heart Association functional class I. Conclusions: Ten- to 20-year survival and functional status are excellent among infants undergoing complete repair of truncus arteriosus. Conduit replacement or revision is almost inevitably necessary in this group of patients. (J Thorac Cardiovasc Surg 1997;113:869-79)
T runcus arteriosus is an uncommon complex cardiovascular malformation that represents approximately $2 \%$ to $4 \%$ of all congenital heart lesions

From the Division of Cardiothoracic Surgery, University of California, San Francisco, San Francisco, Calif.

Dr. Rajasinghe is a recipient of The Thoracic Surgery Foundation for Research and Education Fellowship.

Read at the Seventy-sixth Annual Meeting of The American Association for Thoracic Surgery, San Diego, Calif., April 28-May 1, 1996. in several autopsy series. ${ }^{1,2}$ The distinguishing features of truncus arteriosus include a single arterial trunk that supplies systemic, coronary, and pulmo-

Received for publication May 6, 1996; revisions requested June 18, 1996; revisions received Dec. 18, 1996; accepted for publication Dec. 23, 1996.

Address for reprints: Frank L. Hanley, MD, 505 Parnassus Ave., M589, San Francisco, CA 94143-0118.

Copyright (C) 1997 by Mosby-Year Book, Inc.

$0022-5223 / 97 \$ 5.00+0 \quad \mathbf{1 2 / 6 / 8 0 0 3 6}$ 
Table I. Associated cardiovascular anomalies in patients undergoing complete repair of truncus arteriosus

\begin{tabular}{lcc}
\hline \multicolumn{1}{c}{ Anomaly } & \multicolumn{2}{c}{ Patients } \\
\cline { 2 - 3 } & No. & $\%$ \\
\hline Truncal valve insufficiency & 51 & 31 \\
$\quad$ Mild & 24 & 15 \\
$\quad$ Moderate & 19 & 12 \\
$\quad$ Severe & 8 & 5 \\
Patent foramen ovale or secundum & 37 & 22 \\
$\quad$ atrial septal defect & 29 & 18 \\
Hypoplastic or stenotic pulmonary & & \\
$\quad$ arteries & 16 & 10 \\
$\quad$ Bilateral or main pulmonary & & \\
$\quad$ artery & 13 & 8 \\
$\quad$ Unilateral & 20 & 12 \\
Right aortic arch & 14 & 8 \\
DiGeorge syndrome & 6 & 4 \\
Interrupted aortic arch & 5 & 3 \\
Persistent left superior vena cava & 2 & 1.2 \\
Partial anomalous pulmonary & & \\
$\quad$ venous drainage & 1 & 0.6 \\
Atrioventricular canal defect & 1 & 0.6 \\
Aberrant left subclavian artery & 1 & 0.6 \\
Double-orifice mitral valve & 1 & 0.6 \\
Hypoplastic tricuspid valve & & \\
\hline
\end{tabular}

nary blood flow and an infundibular ventricular septal defect (VSD), both of which are thought to result from failure of proper conotruncal septation. The natural history of this lesion is such that fewer than $25 \%$ of all children born with truncus arteriosus will survive beyond the first year of life without surgical intervention. ${ }^{3}$

The first successful surgical correction of truncus arteriosus was performed in 1967 by McGoon, Rastelli, and Ongley, ${ }^{4}$ who used a valved aortic allograft to establish right ventricular-pulmonary artery continuity. ${ }^{4}$ Over the past three decades, surgical management of truncus arteriosus has evolved to include earlier repair, first during infancy and now primarily in the neonatal period, to avoid the severe morbidity produced by progressive pulmonary vascular obstructive disease. ${ }^{5-8}$ However, long-term follow-up studies have been limited to older children who underwent truncus repair predominantly after primary palliative pulmonary banding operations or, less frequently, who had congenital stenosis of the pulmonary arteries and thus a protected pulmonary vascular bed. ${ }^{9}{ }^{10}$ Few data are available regarding long-term survival and freedom from reintervention after repair of truncus arteriosus in infancy. The purpose of this report was to carefully examine risk factors for adverse long-term outcomes after primary repair of truncus arteriosus at an institution in which a policy of early repair had been adopted and applied to a large number of infants. Because many of these patients have been the subject of previous reports by Ebert, Turley, and their associates, $5,11,12$ who described operative results, early outcomes will not be discussed in the present report.

\section{Patients and methods}

Patients. The study group for the present report consisted of 165 patients who underwent complete repair of truncus arteriosus at the University of California, San Francisco, between 1975 and 1995 and who survived the early postoperative period and had records available for review. Early survivors were defined as patients who were discharged from the hospital and who survived at least 30 days from the time of repair, and early events were defined as events that occurred during the same hospitalization or within 30 days of operation. Medical records could not be located for three known early survivors, and these patients were not included in the 165 -patient cohort. The median age at operation was 3.5 months (range 2 days to 36 years), and $81 \%$ of patients $(n=133)$ were less than 1 year of age (infants). The median weight of patients was $4.3 \mathrm{~kg}$ at the time of the operation and ranged from 2.2 to $52 \mathrm{~kg}$. Seventeen patients $(10 \%)$ were referred to our institution after having undergone one or more previous procedures, including pulmonary artery banding $(n=15)$, repair of interrupted aortic arch $(n=2$; performed with pulmonary artery banding, $n=1)$, systemic-pulmonary artery shunt ( $n=4$; after pulmonary artery banding, $n=3$ ), and pacemaker placement $(n=1)$. Truncus types, according to the Van Praagh classification system, ${ }^{1}$ were type $\mathrm{A} 1$ or $\mathrm{A} 2(n=153)$, type $\mathrm{A} 3(n=6)$, and type A4 (with interrupted aortic arch; $n=6$ ). Associated cardiovascular anomalies are listed in Table I. Data on coronary artery abnormalities, truncal malalignment, truncal valve leaflet structure, and truncal valve stenosis were believed to be inadequate and were not included in the analysis.

Operative procedures. Complete repair of truncus arteriosus was performed with the use of cardiopulmonary bypass in all patients. Median total perfusion time was 76 minutes (range 41 to 433 minutes) but varied considerably among surgeons. Aortic crossclamp times ranged from 0 to 212 minutes (median 30 minutes), with a technique of only partial aortic crossclamping performed in three patients. Total circulatory arrest was used in six patients and ranged in duration from 4 to 55 minutes. The VSD was closed with a patch through a right infundibulotomy. After excision of the pulmonary artery trunk or branch pulmonary arteries from the aorta, patients underwent reconstruction of the right ventricular outflow tract with a porcine valve housed in a synthetic tube $(n=125)$, a cryopreserved aortic $(n=27)$ or pulmonary $(n=12)$ valved allograft conduit, or direct anastomosis of the right ventricle to the main pulmonary artery $(n=1)$. Between 1975 and 1985, all patients except for three (one in 1981 
Table II. Early events in hospital survivors of complete truncus repair

\begin{tabular}{lc} 
Postoperative event variable & $\begin{array}{c}\text { No. of } \\
\text { patients }\end{array}$ \\
\hline Reoperation & 40 \\
For bleeding & 38 \\
Right ventricle-pulmonary artery conduit & 1 \\
$\quad$ revision & 1 \\
$\quad$ Permanent pacemaker placement & 14 \\
Cardiopulmonary arrest (one or more) & 10 \\
Pulmonary hypertensive crisis & 8 \\
Seizures (one or more, clinically evident) & 1 \\
Complete heart block & $4(1$ to 63) \\
Ventilator dependence in days; median & \\
$\quad$ (range) & 15 (7 to 90) \\
Postoperative hospital stay in days; median & \\
$\quad$ (range)
\end{tabular}

"Values indicate number of patients in whom each event/variable occurred; in no case did a single category of event take place more than once in a single patient.

and two in 1982) received synthetic conduits with porcine valves. In 1986, both xenograft and allograft valved conduits were used. Since 1987, allograft valved conduits have been used exclusively, with mainly aortic allografts used until 1991 and pulmonary allografts used preferentially since 1992. The aortic root defect was usually closed primarily, but a glutaraldehyde-treated pericardial patch or a Dacron patch was used to repair large or irregular defects. Ten patients with moderate or severe preoperative truncal valve regurgitation underwent truncal valvuloplasty or annuloplasty $(n=5)$, truncal valve replacement with a mechanical valve $(n=2)$, or truncal root replacement with a cryopreserved allograft aortic root $(n=3)$. Additional procedures performed at the time of truncus repair included repair of interrupted aortic arch $(n=4)$, closure of a patent foramen ovale or secundum atrial septal defect $(n=16)$, pulmonary arterioplasty $(n=$ $4)$, reduction of a dilated truncal root $(n=1)$, mitral valve cleft closure $(n=1)$, coronary artery ostium repair $(n=$ $1)$, and right ventricular outflow tract muscle resection $(n=1)$.

Data collection and statistical analysis. Preoperative and perioperative data were collected on retrospective review of patient records. Follow-up was carried out by means of physician or patient contact and was completed by February 1996. SPSS for Windows version 6.01 (SPSS Inc., Chicago, Ill.) was used to perform statistical calculations. Data are expressed as median and either range or 95\% confidence intervals (CI). The Kaplan-Meier product limit method and Cox proportional hazards regression methods were used for actuarial survival analysis and analysis of freedom from reoperation (all reoperations, conduit reoperations, and truncal valve reoperations). Multiple regression analysis was performed as conditional backward stepwise proportional hazards regression. Patients lost to follow-up were censored from survival and
Table III. Causes of late death $(n=23)$ in hospital survivors of complete truncus repair

\begin{tabular}{|c|c|c|}
\hline Cause of death & $\begin{array}{l}\text { Duration } \\
\text { after repair } \\
\quad(\text { mo })\end{array}$ & $\begin{array}{l}\text { Age at } \\
\text { repair } \\
\text { (mo) }\end{array}$ \\
\hline Arrhythmia & 2 & 1.9 \\
\hline Pneumonia & 2 & 3.2 \\
\hline RSV infection, sepsis, respiratory arrest & 2 & 1.9 \\
\hline $\begin{array}{l}\text { Acute LV failure after truncal valve re- } \\
\text { placement for severe truncal valve insuf- } \\
\text { ficiency* }\end{array}$ & 2 & 1.9 \\
\hline $\begin{array}{l}\mathrm{CP} \text { arrest, as a result of bacterial endocar- } \\
\text { ditis (possible conduit malfunction) }\end{array}$ & 3 & 13.2 \\
\hline $\begin{array}{l}\text { Could not be weaned from CPB during } \\
\text { third residual VSD repair* }\end{array}$ & 4 & 1.6 \\
\hline $\begin{array}{l}\text { CP arrest after repair of residual VSD, } \\
\text { with pneumonia and sepsis* }\end{array}$ & 4 & 1.5 \\
\hline Sudden respiratory distress and CP arrest & 6 & 2.9 \\
\hline $\begin{array}{l}\text { Global cerebral damage and sepsis after } \\
\text { truncal valve replacement* }\end{array}$ & 7 & 4.2 \\
\hline Sudden respiratory distress and CP arrest & 8 & 0.1 \\
\hline $\begin{array}{l}\text { Truncal valve prosthesis became lodged } \\
\text { open, massive truncal valve insufficiency }\end{array}$ & 8 & 0.2 \\
\hline Sudden respiratory distress and CP arrest & 11 & 7.6 \\
\hline CP arrest after conduit reoperation* & 11 & 2.8 \\
\hline $\begin{array}{l}\text { Could not be weaned from CPB during } \\
\text { conduit reoperation* }\end{array}$ & 34 & 1.9 \\
\hline $\begin{array}{l}\text { Subarachnoid hemorrhage, one day after } \\
\text { conduit reoperation* }\end{array}$ & 46 & 1.3 \\
\hline $\begin{array}{l}\mathrm{CP} \text { arrest (obscure proximal cause; } 2.5 \\
\text { weeks after jellyfish sting) }\end{array}$ & 52 & 0.9 \\
\hline $\begin{array}{l}\text { Irreversible PVOD (not transplant candi- } \\
\text { date) }\end{array}$ & 60 & 77 \\
\hline $\begin{array}{l}\text { Hepatic failure caused by DPH toxicity (af- } \\
\text { ter grand mal seizure) }\end{array}$ & 66 & 3 \\
\hline $\begin{array}{l}\text { CP arrest after second truncal valve re- } \\
\text { placement and residual VSD closure* }\end{array}$ & 78 & 35 \\
\hline $\begin{array}{l}\text { Could not be weaned from CPB during } \\
\text { second reoperation (conduit reoperation) }\end{array}$ & 105 & 2.7 \\
\hline Renal failure after myocardial infarction & 117 & 432 \\
\hline $\begin{array}{l}\text { Pulmonary edema, rule out Pneumocystis } \\
\text { pneumonia }\end{array}$ & 117 & 8 \\
\hline $\begin{array}{l}\mathrm{CP} \text { arrest during reoperation for bleeding } \\
\text { after third reoperation (conduit reopera- } \\
\text { tion)* }\end{array}$ & 139 & 1.6 \\
\hline
\end{tabular}

* Reoperation related. $R S V$, Respiratory syncytial virus; $L V$, left ventricular; $C P$, cardiopulmonary; $C P B$, cardiopulmonary bypass; $V S D$, ventricular septal defect; $P V O D$, pulmonary vascular obstructive disease; $D P H$, diphenhydramine.

freedom from reoperation analyses at the time they were lost to follow-up. Independent variables analyzed are listed in the appendix.

\section{Results}

Early reoperations, complications, and hospital outcomes among study group patients are summarized in Table II. 


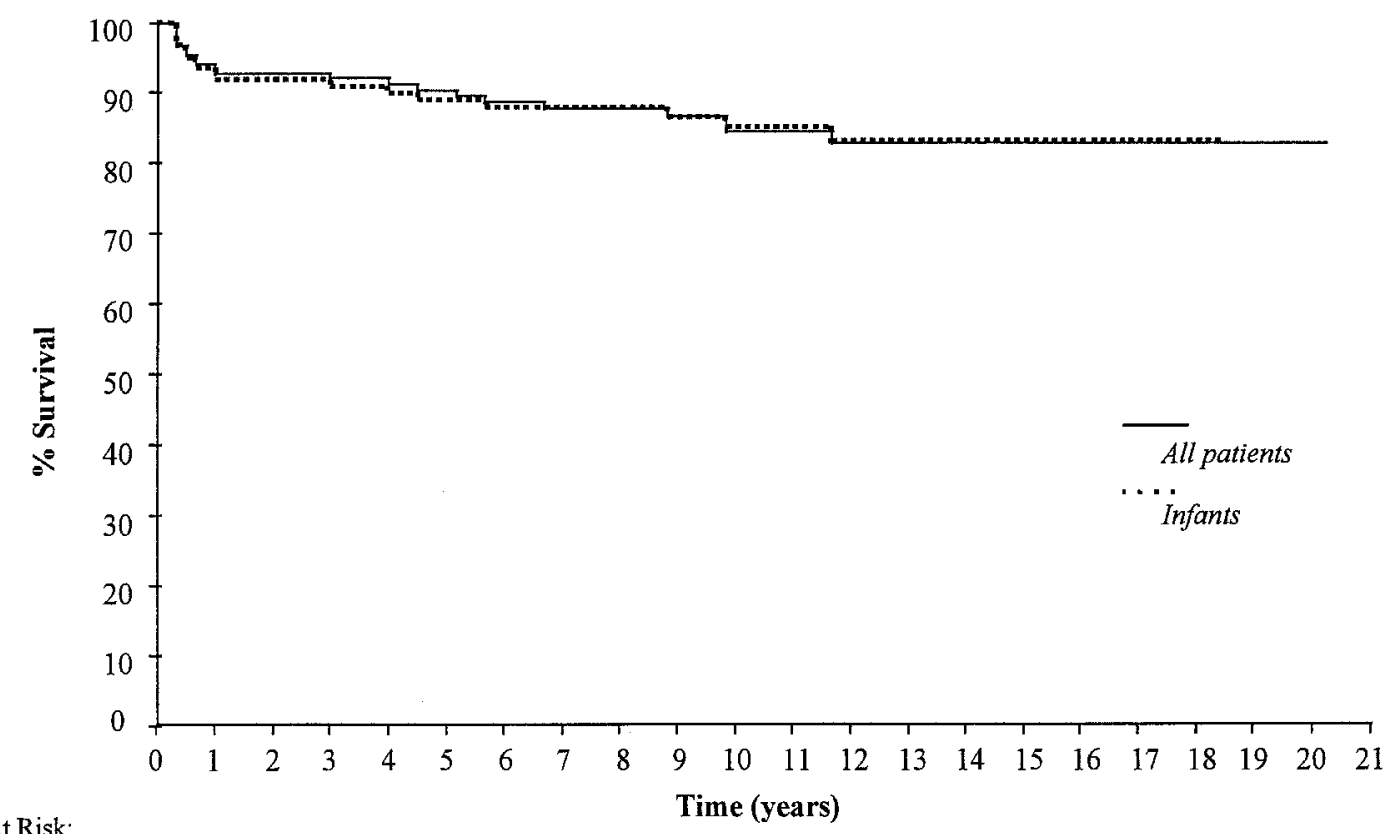

At Risk:

\section{Time (years)}

$\begin{array}{lrrrrrrrrrrrrrrrrrrrrr}\text { All patients } & 165 & 137 & 128 & 121 & 114 & 110 & 104 & 101 & 93 & 83 & 70 & 61 & 44 & 39 & 24 & 16 & 7 & 6 & 3 & 1 & 1 \\ \text { Infants } & 133 & 110 & 103 & 98 & 92 & 88 & 83 & 81 & 74 & 68 & 57 & 52 & 35 & 30 & 18 & 11 & 4 & 3 & 1 & \end{array}$

Fig. 1. Actuarial survival among hospital survivors of complete truncus repair. Survival curves are shown for all patients and for infants (patients under 1 year of age at repair).

Table IV. Factors found to be significantly associated with decreased survival by univariate and multiple proportional hazards regression analysis

\begin{tabular}{|c|c|c|c|c|}
\hline \multirow[b]{2}{*}{ Variable } & \multicolumn{2}{|c|}{ Univariate analysis } & \multicolumn{2}{|c|}{ Multiple regression analysis } \\
\hline & $\begin{array}{c}\text { Hazard ratio } \\
(95 \% C I)\end{array}$ & $p$ Value & $\begin{array}{c}\text { Hazard ratio } \\
(95 \% \mathrm{Cl})\end{array}$ & $p$ Value \\
\hline Age $<3$ mo & $\begin{array}{c}0.59 \\
(0.38-0.92)\end{array}$ & 0.02 & $\begin{array}{c}0.86 \\
(0.10-1.48)\end{array}$ & 0.59 \\
\hline $\begin{array}{l}\text { Aortic crossclamp time } \\
\text { (continuous) }\end{array}$ & $\begin{array}{c}0.92 \\
(0.86-0.99)\end{array}$ & 0.02 & $\begin{array}{c}0.92 \\
(0.85-0.99)\end{array}$ & 0.03 \\
\hline $\begin{array}{l}\text { Postoperative hospital stay } \\
\text { (continuous) }\end{array}$ & $\begin{array}{c}1.03 \\
(1.01-1.05)\end{array}$ & 0.006 & $\begin{array}{c}1.01 \\
(0.99-1.04)\end{array}$ & 0.26 \\
\hline Interrupted aortic arch & $\begin{array}{c}2.85 \\
(1.33-6.11)\end{array}$ & 0.007 & $\begin{array}{c}5.43 \\
(1.71-17.25)\end{array}$ & 0.004 \\
\hline $\begin{array}{l}\text { Moderate or severe prerepair } \\
\text { truncal valve regurgitation }\end{array}$ & $\begin{array}{c}1.75 \\
(1.09-2.82)\end{array}$ & 0.02 & $\begin{array}{c}1.84 \\
(1.02-3.34)\end{array}$ & 0.04 \\
\hline
\end{tabular}

Follow-up and survival. Patients were followed up for a median of 10.5 years (range 0.1 to 20.4 years). Twenty-five patients were lost at cross-sectional follow-up, but a median of 1.1 years of follow-up (range 1 month to 12 years, total 67 patient-years) was available on these patients. Twenty-three patients died during the follow-up period; causes of death are listed in Table III. Thirteen of the 23 late deaths $(57 \%)$ occurred within 1 year of truncus repair. Ten patients died early after reoperations for conduit replacement $(n=5)$, isolated truncal valve replacement $(n=2)$, isolated residual VSD closure $(n=2)$, or a second truncal valve replacement with residual VSD closure $(n=1)$. Eleven late deaths occurred before any reoperation. Actuarial survival was $90 \%$ at 5 years, $85 \%$ at 10 years, and $83 \%$ at 15 and 20 years after repair (Fig. 1). Among infants, actuarial survival was almost identical, with $90 \%$ at 5 years, $87 \%$ at 10 years, and $83 \%$ at 15 years (Fig. 1). Factors signifi- 


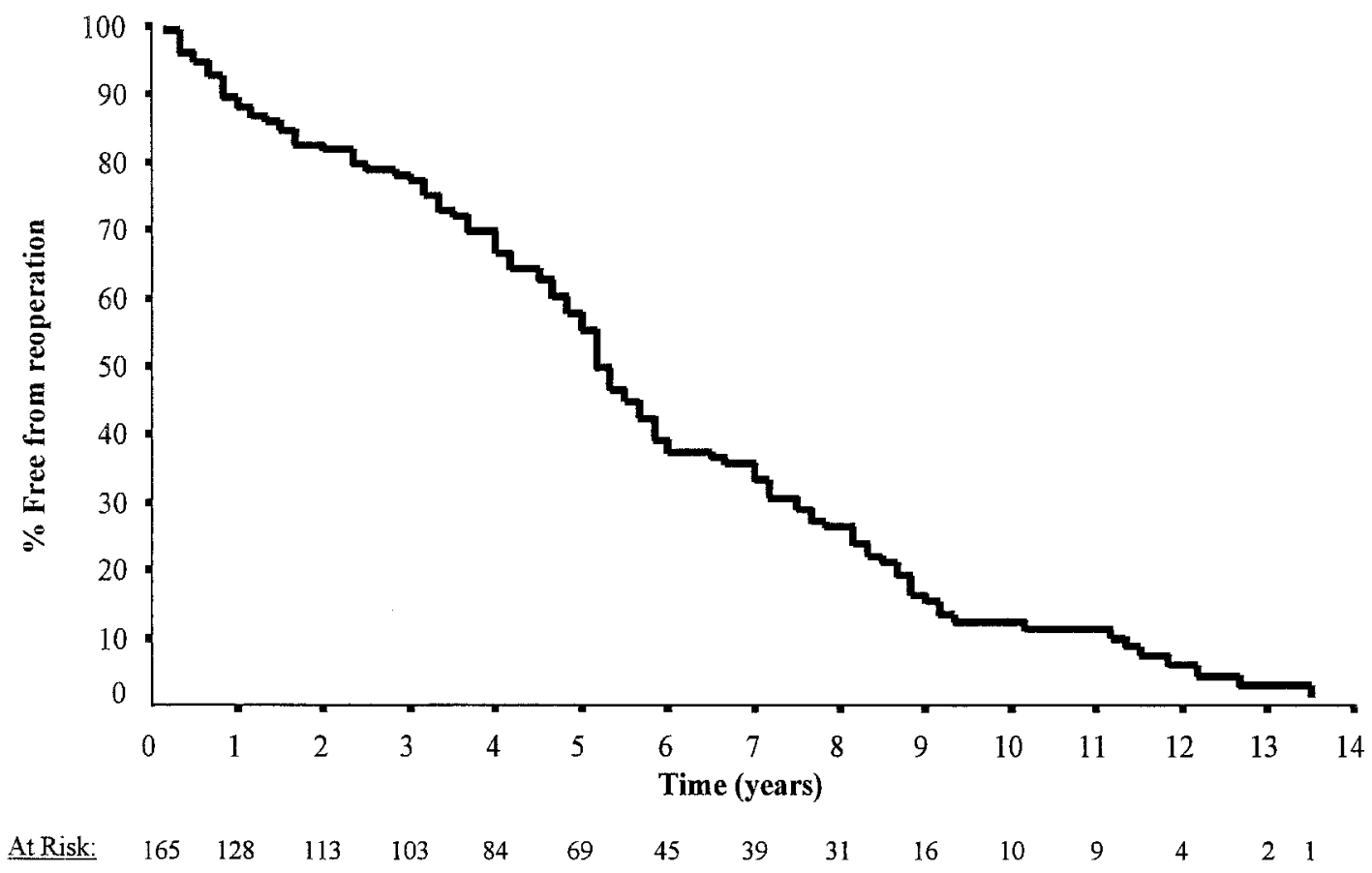

Fig. 2. Actuarial freedom from reoperation after repair of truncus arteriosus.

cantly associated with decreased survival by univariate and multivariate analysis are listed in Table IV. Eight of the 23 late deaths occurred in patients with moderate or severe prerepair truncal insufficiency, including five of the 13 patients who died within 1 year of repair. Three of the patients with interrupted arch died during the follow-up period, all within 16 months of the operation. All surviving patients were in New York Heart Association class I at follow-up, except for three patients with decreased exercise tolerance, who were in class II.

Reoperations. During the follow-up period, 119 patients underwent a total of 164 reoperations. Many of these were performed at other institutions. The median time to reoperation after initial truncus repair was 5.1 years $(95 \% \mathrm{CI}, 4.7$ to 5.5 years; Fig. 2). Factors significantly associated with shorter duration to reoperation were the same as those for conduit reoperation (discussed later). Ten patients died early after reoperation, for a reoperation mortality rate of $6.1 \%(10 / 164)$. None of the factors analyzed was significantly associated with death after reoperation, and there have been no reoperation-related deaths since 1989.

Conduit reoperations. At the time of cross-sectional follow-up, 107 patients had undergone a total of 133 conduit reoperations (replacement or revision). Twenty patients had undergone multiple con- duit reoperations, including five patients in whom three or four conduit replacements had been performed. Five patients died at the time of conduit reoperation for an overall mortality of $3.8 \%(5 / 133)$ related to conduit replacement. The median right ventricle-pulmonary artery gradient at the time of first conduit replacement was $61 \mathrm{~mm} \mathrm{Hg}$ (range 15 to $156 \mathrm{~mm} \mathrm{Hg}$ ). Median time to conduit reoperation was 5.5 years (95\% CI, 4.9 to 6.1 years). By univariate proportional hazards regression analysis, age less than 3 months (hazard ratio $=1.45$ [95\% CI, 1.19 to 1.79$] ; p=0.0003$ ), smaller conduit size (hazard ratio for conduit size as a continuous variable $=0.82[95 \% \mathrm{CI}, 0.73$ to 0.91$]$; $p=0.0001$ ), and lower weight at the time of complete truncus repair (hazard ratio for weight as a continuous variable $=0.93[95 \% \mathrm{CI}, 0.87$ to $0.99] ; p=0.02$ ) were significantly associated with shorter duration to conduit reoperation. On multivariate analysis, weight fell out of the equation, leaving age less than 3 months (hazard ratio= 0.79 [95\% CI, 0.63 to 0.98 ] $p=0.03$ ) and smaller conduit size (hazard ratio for conduit size as a continuous variable $=0.87$ [95\% CI, 0.77 to 1.03$]$; $p=0.009$ ) as independent risk factors for shorter duration to conduit reoperation. Fig. 3 depicts the difference in freedom from conduit reoperation between patients less than and greater than 3 months of 


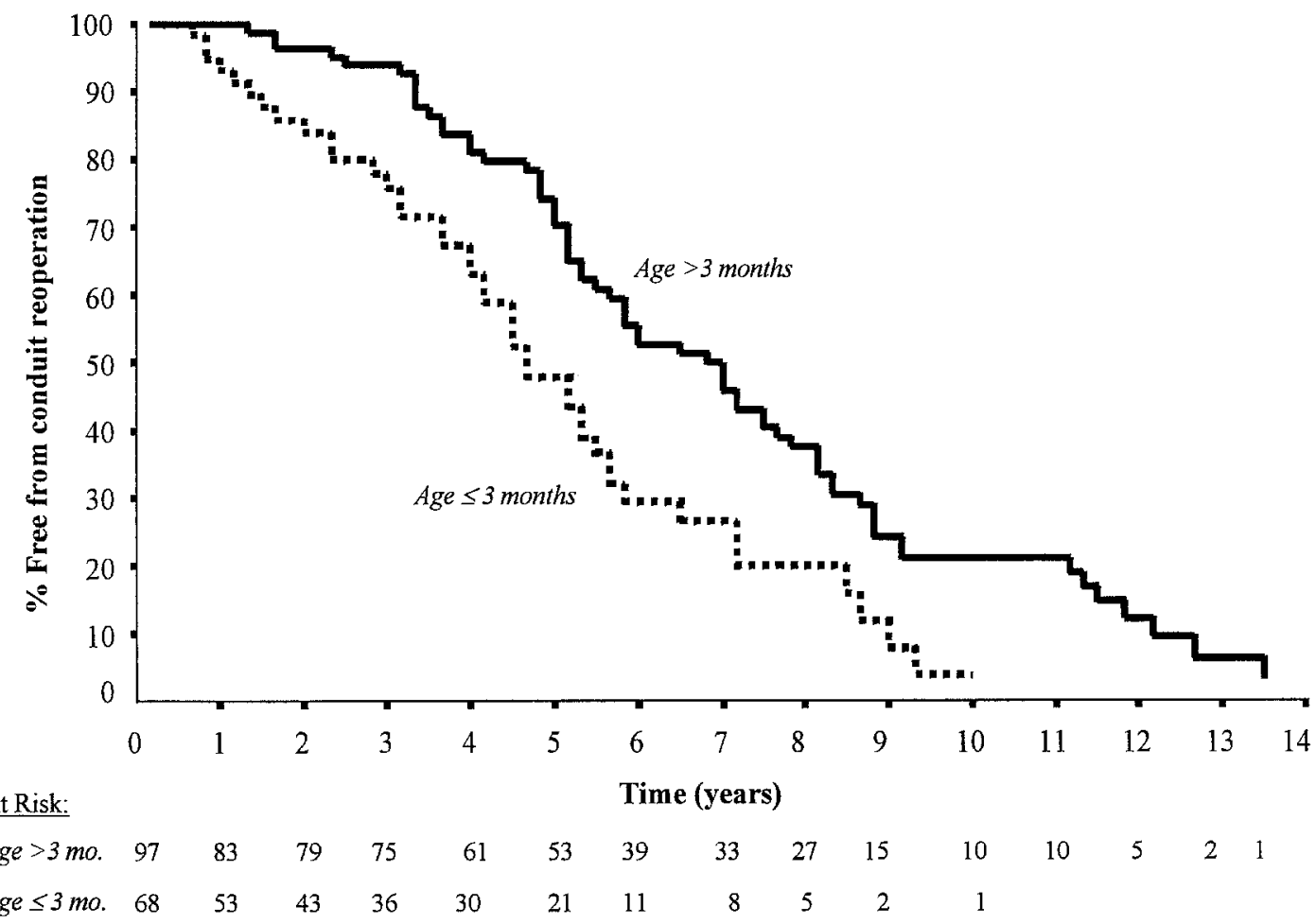

Fig. 3. Actuarial freedom from conduit reoperation (replacement or revision) in patients less than and greater than 3 months of age at the time of truncus arteriosus repair. Median freedom from conduit reoperation in patients greater than 3 months at repair was 82 months (95\% CI, 67 to 97 months). Median freedom from conduit reoperation in patients under 3 months at repair was 55 months (95\% CI, 45 to 65 months).

age at initial truncus repair. There was no significant difference in time to conduit replacement when comparing patients who received synthetic versus allograft conduits $(p=0.90)$.

Truncal valve reoperations. During the follow-up period, 26 patients underwent a total of 30 truncal valve replacements (four patients had two replacements each). Truncal valve replacement (the initial replacement in those who had two truncal valve replacements) was performed as a first reparative procedure without conduit replacement in six patients, as a first reoperation along with conduit reoperation in 16 patients, as a second reoperation along with a second conduit replacement in two patients, as a third procedure in one patient, and as a fourth procedure along with a fourth conduit reoperation in one patient. Replacement valves were mechanical in 26 patients and aortic root allografts in four patients. In one patient, a Konno left ventricular outflow tract enlargement was performed at the time of a second truncal valve replacement. Three patients died early after a reoperation that involved truncal valve replacement, including two patients who died alter isolated truncal valve replacement as a first reoperation and one patient who died after a second truncal valve replacement. Another patient died 2 months after uneventful truncal valve replacement, after the mechanical replacement valve became lodged in the open position, leading to massive truncal insufficiency and left-sided failure. Overall freedom from truncal valve replacement was $95 \%$ at 2 years, $91 \%$ at 5 years, $84 \%$ at 10 years, and $68 \%$ at 15 years after truncus repair (Fig. 4). The only independent risk factor for earlier truncal valve replacement was prerepair truncal valve insufficiency $(p<0.0001$; Fig. 4).

Other reoperations. Branch pulmonary arterioplasty was performed at the time of conduit reoperation in 18 patients and before conduit reoperation in 14 patients (four surgical, 10 percutaneous). A residual VSD was closed in 19 patients: before any other reoperation in three patients (two of whom required second and third procedures to close 


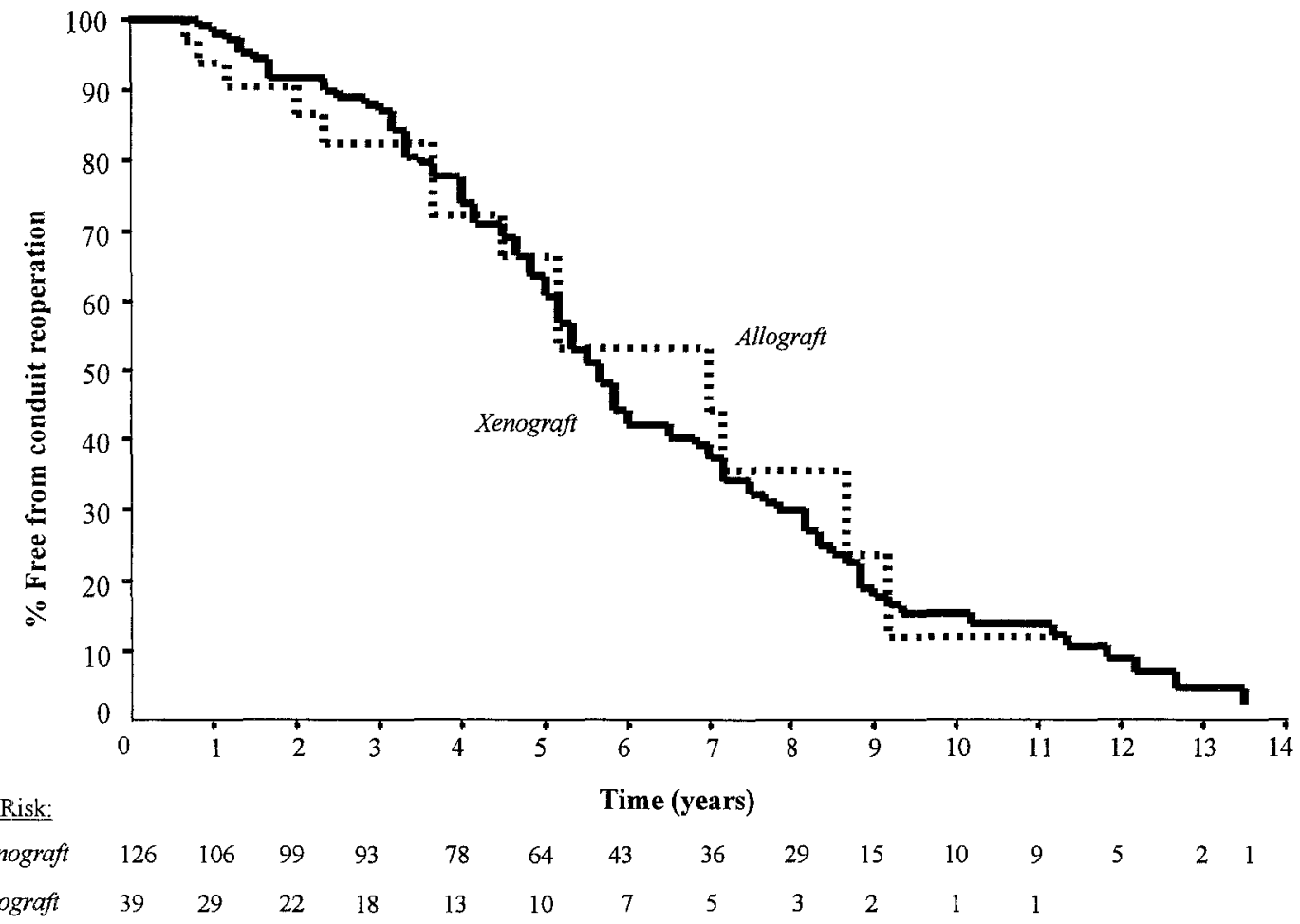

Fig. 4. Actuarial freedom from conduit reoperation according to the type of right ventricle-pulmonary artery conduit used at initial truncus repair.

recurrent residual VSDs), and with conduit ( $n=15)$ or truncal valve $(n=1)$ reoperation in 16 patients. Residual atrial septal defect closure was performed along with conduit replacement in five patients. One patient underwent repair of cor triatriatum, mitral valve cleft, and a defect in the ascending aorta resulting from conduit erosion, all at the time of a second conduit reoperation. One patient underwent placement of a permanent sequential atrioventricular pacemaker after the development of a hemodynamically unstable second-degree heart block after conduit reoperation.

\section{Discussion}

The impetus that stimulated early surgical correction of truncus arteriosus was recognition that as children were allowed to grow older they became unsuitable surgical candidates because of the development of progressive pulmonary vascular obstructive disease. Early reports of truncus repair from the Mayo Clinic experience showed a correlation between increasing early mortality and higher levels of pulmonary vascular resistance. ${ }^{3}$ Ebert and associates $^{5}$ showed that early surgical correction of truncus arteriosus in infancy could be undertaken safely with low morbidity and mortality. More recent reports by Hanley, ${ }^{7}$ Bove, ${ }^{6}$ and their associates demonstrated that elective repair in the neonatal period was not only feasible but preferable. In current surgical practice, early primary repair of truncus arteriosus is the standard approach to treatment of this lesion. To date, however, little information is available on the long-term results of such a policy.

This report specifically examined the long-term survival of a large group of patients who underwent early truncus arteriosus repair at a single institution. Although a number of the patients included in the present cohort were neonates, most were not, and thus our study group is not entirely representative of most patients undergoing truncus repair in the current era. A total of 165 long-term survivors undergoing repair at a median age of 3.5 months were followed up for up to 20 years. Late survival rates were $90 \%, 85 \%$, and $83 \%$ at 5,10 , and 15 years, respectively, with the overwhelming majority of these patients in excellent health. Of the 23 late deaths in our experience, the majority $(57 \%, 13 / 23)$ occurred within the first year after discharge from the hospital after truncus repair: Five were related to residual defects at reoperation; three were the 


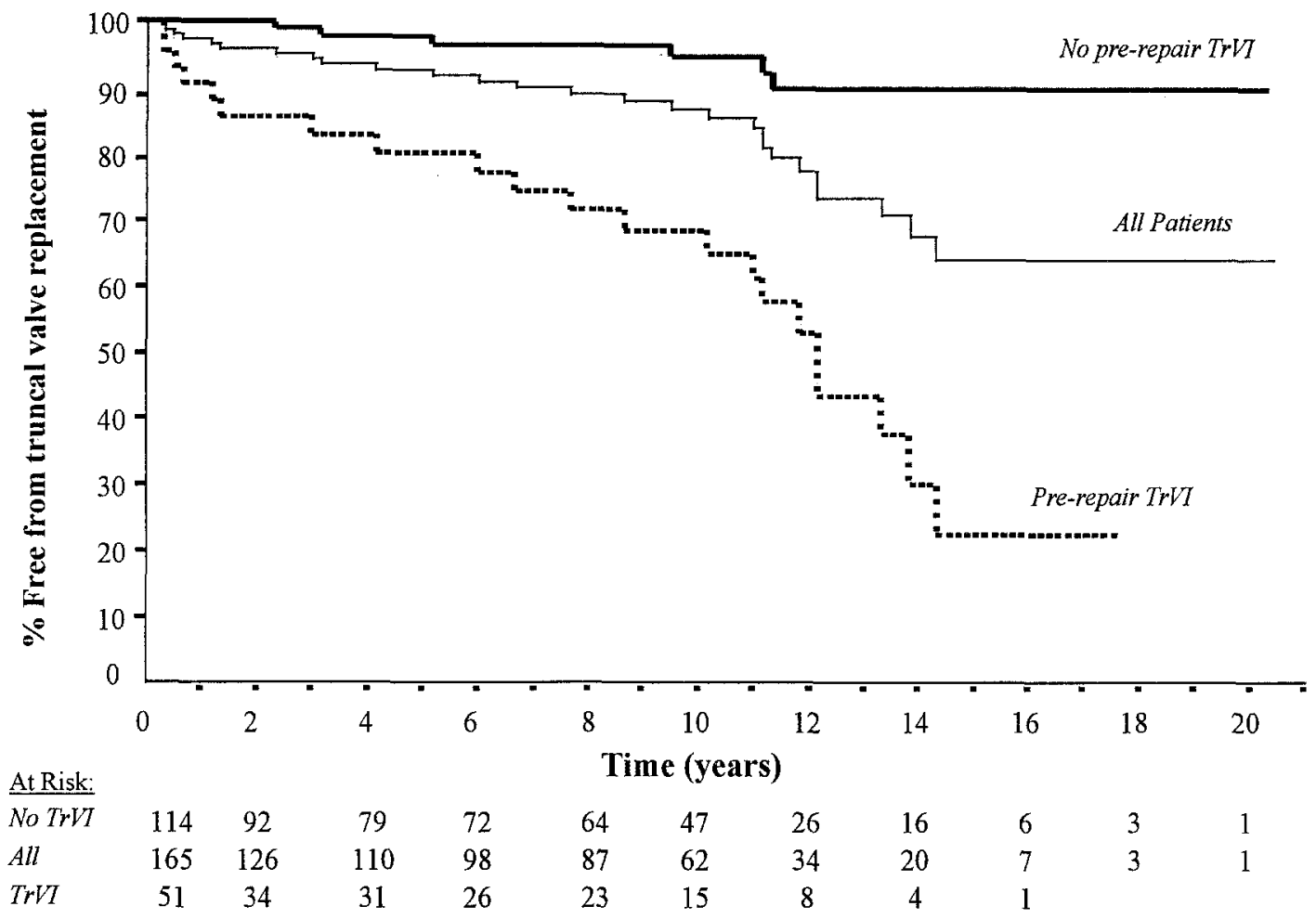

Fig. 5. Actuarial freedom from truncal valve replacement in all patients and in patients with and without truncal valve insufficiency ( $\operatorname{Tr} V I$ ) before complete truncus repair.

result of sudden cardiopulmonary arrests; three were of an infectious origin; and one death each resulted from a mechanical valve dysfunction and rhythm disturbance. These results compare favorably with previously published long-term survival studies.., 10

Of 30 independent variables analyzed for association with long-term outcomes, prerepair truncal valve insufficiency of moderate or greater degree, interrupted aortic arch, and shorter crossclamp time were found to correlate significantly with poorer survival by multivariate Cox regression analysis. Patients with preoperative truncal insufficiency or interrupted aortic arch (or both) accounted for 10 of the 23 late deaths and half of the deaths occurring within 1 year of repair. The association of shorter crossclamp time with poorer time-related survival was likely an artifact, because this variable was confounded by the great variation in cardiopulmonary bypass and aortic crossclamp times between surgeons and across the study period. In addition, inasmuch as very few patients with interrupted aortic arch were included in this cohort, it is doubtful that any conclusions can be drawn regarding the association between interrupted arch and long-term prognosis. Among the 23 late deaths in this experience, only one was attributable to the development of irreversible pulmonary vascular obstructive disease. This occurred in a patient who underwent truncus repair at the age of 6.4 years and died 5 years after the operation, at which time the patient was not deemed a transplant candidate. This is in sharp contrast to the early Mayo Clinic experience, in which more than $40 \%$ (9/21) of late deaths were associated with the presence of pulmonary vascular obstructive disease and in which progression of pulmonary vascular obstructive disease was found to increase the risk of late death. ${ }^{10}$ This difference in late mortality is likely explained by the significant difference in the distribution of ages at which patients underwent truncus repair between the two studies ( 3.5 months vs 6 years). These results demonstrate for the first time that adoption of a policy of early truncus repair to avoid the early morbidity and hospital mortality associated with progressive pulmonary vascular obstructive disease appears to have a favorable influence on long-term survival as well.

A significant proportion of late deaths $(10 / 23)$ 
occurred at reoperation for conduit replacement, truncal valve replacement, or residual VSD closure. The overall mortality from conduit replacement was $3.8 \%$. Although it was difficult to assess risk factors for poor outcome after late reintervention, owing in large part to the fact that many of the reoperations were performed at other institutions, there were no significant predictors of reoperation-related mortality. Nevertheless, there have been no deaths related to reintervention since 1989 .

A large majority of the patients in this experience, particularly those operated on during the years 1975 to 1985 , received xenograft valved synthetic conduits. After 1987, valved allografts were exclusively used for repair. However, there was no significant difference in time to conduit replacement between synthetic conduits and allografts when patients were viewed in aggregate. Only younger age and smaller conduit size were independent risk factors for shorter time to conduit reoperation, reflecting the largely younger age of patients undergoing repair. Numerous studies, including an age-matched comparison we have reported previously, have shown improved durability of truncus arteriosus repair with cryopreserved allograft valves. ${ }^{13,14}$ However, direct comparisons with our own overall experience may be difficult to make because of many uncontrolled variables, most important, the issue of specific hemodynamic indications for conduit replacement. Nevertheless, valved homografts may offer superior performance and are generally believed to be more appropriate for neonatal repair, particularly when considering technical issues related to sternal closure and anastomosis of the conduit to thin friable pulmonary arteries. Whether a synthetic or allograft conduit is used for early truncus repair, though, we may surmise from our experience that the need for late conduit reintervention is almost inevitable.

Although the natural history of truncal insufficiency after primary truncus repair is not widely known, truncal valve insufficiency remained a significant source of long-term morbidity in our followup. In our experience, concomitant truncal valve replacement or repair at the time of initial truncus repair was done only in the most severe forms of truncal valve regurgitation. Any degree of prerepair truncal valve regurgitation (mild, moderate, or severe) was found to be a significant predictor of subsequent truncal valve replacement. The absence of any preoperatively detectable truncal valve insufficiency made the likelihood of truncal valve replacement extremely low, but not zero. Furthermore, moderate to severe truncal valve regurgitation was an independent risk factor for poorer long-term survival.

In conclusion, 10- to 20-year survival and functional status are excellent among infants undergoing complete repair of truncus arteriosus. Predictably, conduit replacement or revision is almost invariably necessary. Patients with truncal insufficiency who do not undergo truncal valve repair or replacement at initial truncus repair are at significantly higher risk for late truncal valve replacement and should be monitored closely for evidence of increasing truncal valve dysfunction, especially in the early postoperative period.

\section{REFERENCES}

1. Van Praagh R, Van Praagh S. The anatomy of common aorticopulmonary trunk (truncus arteriosus communis) and its embryologic implications. Am J Cardiol 1965;16: 406-25.

2. Calder L, Van Praagh R, Van Praagh S, et al. Truncus arteriosus communis. Clinical, angiographic, and pathologic findings in 100 patients. Am Heart J 1976;92:23-38.

3. Marcelletti C, McGoon DC, Mair D. The natural history of truncus arteriosus. Circulation 1976;54:108-11.

4. McGoon DC, Rastelli GC, Ongley PA. An operation for the correction of truncus arteriosus. JAMA 1968;205:69-73.

5. Ebert PA, Turley K, Stanger P, Hoffman JIE, Heymann MA, Rudolph AM. Surgical treatment of truncus arteriosus in the first 6 months of life. Ann Surg 1984;200:451-6.

6. Bove E, Beekman R, Snider, et al. Repair of truncus arteriosus in the neonate and young infant. Ann Thorac Surg 1989;47:499-506.

7. Hanley FL, Heinemann MK, Jonas RA, et al. Repair of truncus arteriosus in the neonate. $J$ Thorac Cardiovasc Surg 1993; 105:1047-56.

8. Lacour-Gayet F, Serraf A, Komiya T, et al. Truncus arteriosus repair: influence of techniques of right ventricular outflow tract repair. J Thorac Cardiovasc Surg 1996;111:849-56.

9. Marcelletti C, McGoon DC, Danielson GK, Wallace RB, Mair DD. Early and late results of surgical repair of truncus arteriosus. Circulation 1977;55:636-41.

10. Di Donato RM, Fyfe DA, Puga FJ, et al. Fifteen-year experience with surgical repair of truncus arteriosus. J Thorac Cardiovasc Surg 1985;89:414-22.

11. Boyce SW, Turley K, Yee ES, Verrier ED, Ebert PA. The fate of the $12 \mathrm{~mm}$ porcine valved conduit from the right ventricle to the pulmonary artery. J Thorac Cardiovasc Surg 1988:95:201-7.

12. Turley K, Turley K, Ebert PA. Aortic allografts: reconstruction of right ventricle-pulmonary artery continuity. Ann Thorac Surg 1989;47:278-81.

13. Schaff HV, DiDonato RM, Danielson GK, et al. Reoperation for obstructed pulmonary ventricle-pulmonary artery conduits: early and late results. J Thorac Cardiovasc Surg 1984;88:334-43.

14. Reddy VM, Rajasinghe HA, McElhinney DB, Hanley FL. 
Performance of right ventricle to pulmonary artery conduits after repair of truncus arteriosus: a comparison of Dacronhoused porcine valves and cryopreserved allografts. Sem Thorac Cardiovasc Surg 1995;7:133-8.

\section{Discussion}

Dr. Gordon K. Danielson (Rochester, Minn.). The authors are to be congratulated for their comprehensive analysis and superb results. The treatment of truncus arteriosus has come a long way since the first successful repair by Dr. Dwight McGoon at the Mayo Clinic in September 1967. An irradiated aortic homograft was used to establish right ventricle-pulmonary artery continuity. The philosophy in those early years of repair was to delay operation in infants for as long as possible to allow them to grow older so that they would "tolerate the procedure better." As a result, infants were being sent for operation when they were either in intractable cardiac failure or had pulmonary vascular obstructive disease, and the results were far from ideal. Dr. Ebert and associates at the authors' institution pioneered early surgical repair for truncus and showed that the risks for repair in infancy were actually less than for older patients. For many years, at each update of their series, the operative risk for repair in patients under the age of 6 months was about half the risk for repair between 6 and 12 months. Dr. Hanley's group has nicely shown that late survival is also improved by early repair, particularly by abolishing the attrition that occurs when patients already have pulmonary vascular obstructive disease at the time of repair. Pulmonary vascular obstructive disease, and the progression thereof, in our early series of patients accounted for $40 \%$ of the late deaths.

There are many interesting aspects of this report that could be discussed. Time constraints limit my comments to two late complications that are yet to be resolved. The first is the problem of late conduit stenosis. It is of interest that the authors have found no significant difference in time to conduit replacement between porcine-valved Dacron conduits and cryopreserved homografts. This is similar to our finding that cryopreserved aortic homografts are no better than previous conduits.

[Slide] Survivorship free from conduit failure for cryopreserved aortic homografts in our experience is shown in the orange line, directly overlying the line for irradiated aortic homografts, which had the worst outcome of all the conduits we have used. It is interesting that porcine-valved Dacron conduits actually had better freedom from conduit failure. The pulmonary homografts tended not to calcify as rapidly as aortic homografts. However, if one includes anastomotic aneurysms and the development of valvular insufficiency in the definition of conduit failure, the survivorship for pulmonary homografts looks similar to that for aortic homografts. It is reassuring, however, that the risk for conduit change alone, as the authors have indicated, is small and has little adverse effect on late patient survival.

The second consideration is late development of aortic or truncal valve insufficiency. Even though truncal insufficiency may be absent or only mild after repair, it may progress relentlessly, requiring operation for correction. The same phenomenon is seen after repair of pulmonary atresia, but to a lesser extent. It is interesting that in both conditions, the aorta is dilated from carrying all of the pulmonary and systemic blood flow, and this may be a mechanism for development of aortic valve insufficiency.

I notice that the aortic valve was replaced in all of the reoperations for aortic insufficiency in the authors' report. With newer techniques of aortic valve repair, do the authors believe satisfactory repair of the truncal valve will also be possible? Have they considered performing an annuloplasty if only mild or moderate truncal valve insufficiency is present, perhaps at the time of conduit change, and do they think this might help delay or prevent late reoperation for severe aortic valve insufficiency?

Dr. Rajasinghe. Thank you very much, Dr. Danielson. With regard to conduit reoperations and late conduit stenosis, I completely agree with you. In our experience, as in yours, the fact that there was no significant difference in time to conduit replacement based on conduit type reflects a number of factors, many of which could not be controlled. One is specific hemodynamic indications for the conduit replacement: this may be quite variable depending on the surgeon. Furthermore, there was a significant difference in age distribution between the groups of study in your paper, as well as in our experience. Our patients tended to be younger and were under 6 months of age predominantly, and they were several years older in the Mayo Clinic experience. I do believe, though, that all of these conduits eventually will have to be replaced, and that can be undertaken with very low mortality.

With regard to the truncal valve and very mild degrees of insufficiency, I do not have a uniform policy to apply at the time of truncus repair; however, I do believe that it is important to carefully inspect and address the truncal valve, because even mild regurgitation can progress over time and require subsequent valve replacement. The anatomy of the truncal valve can be quite variable. The valve has anywhere from two to six leaflets and can be extremely dysmorphic. In those instances in which the valve is extremely dysmorphic, it may well prove worthwhile to perform an annuloplasty for mild insufficiency at the time of complete truncus repair. I believe this will help delay the development of late aortic insufficiency. Ultimately, the decision to perform an annuloplasty will be an operative one, and the judgment of the surgeon will be of critical importance. Our data support your observation that the presence of preoperative truncal valve insufficiency is a significant risk factor for subsequent valve replacement.

Dr. Miguel Barbero Marcial (São Paulo, Brazil). At the Heart Institute of São Paulo, since 1987, we have been following a different policy for correction of truncus, that is, we are not using an extracardiac conduit in truncus type 1 or $1 \frac{1}{2}$. In a total series of 45 patients, we have an early mortality of 12 patients, $26 \%$; and two unrelated late deaths. Reoperation to relieve pulmonary stenosis was necessary in only two of the 31 long-term survivors. To decrease the immediate mortality of $26 \%$, since 1993 we have been doing this operation only in neonates and infants less than 5 months of age. To avoid massive pulmonary regurgitation during hypertensive crises in the postoperative period, we are placing the new commer- 
cially available monocusp in the high position of the new outflow tract of the right ventricle. Among the 12 patients operated on in this recent period, we have only one immediate death.

I would like to ask Dr. Rajasinghe if he considered coronary anomalies, mainly the ostium stenosis, as a risk factor for the immediate or late postoperative course.

Dr. Rajasinghe. Thank you. We did not specifically examine coronary artery anomalies in our experience as an independent risk factor, in large measure because the data from our medical records were believed to be inadequate with poor documentation at times. However, a number of previously published studies, including a series from Boston Children's Hospital several years ago by Dr. Hanley, showed that coronary artery anomalies were a risk for early mortality and reduced intermediate-term survival as well. I think this information should be closely kept and monitored in addition to the presence of an interrupted aortic arch and the presence of truncal valve insufficiency.

\section{Appendix}

Independent variables analyzed by Cox proportional hazards regression analysis for correlation with late events after complete repair of truncus arteriosus:

\section{Demographic variables}

Year of operation

Age at operation

Continuous

Less than 3 months (yes/no)

Weight at operation

Previous palliative procedure (yes/no)

\section{Morphologic variables}

Truncus type other than Van Praagh AI or A2 (yes/no)

Truncal valve insufficiency

Mild or greater (yes/no)

Moderate or greater (yes/no)

Atrial septal defect or patent foramen ovale (yes/no)

Interrupted aortic arch (yes/no)

Right aortic arch (yes/no)

DiGeorge syndrome (yes/no)

Hypoplastic or stenotic branch pulmonary arteries (yes/no)

Other cardiac anomalies (yes/no)

Operative variables

Cardiopulmonary bypass time

Aortic crossclamp time

Circulatory arrest (yes/no)

Conduit type (synthetic/allograft)

Conduit size (diameter)

Continuous

Less than $12 \mathrm{~mm}$ (yes/no)

Truncal valve replacement or repair (yes/no)

Interrupted aortic arch repair (yes/no)

Additional surgical procedure (yes/no)

Early postoperative variables

Reoperation

All cardiac (yes/no)

For bleeding (yes/no)

Pulmonary hypertensive crisis (yes/no)

Complete heart block (yes/no)

Cardiopulmonary arrest (yes/no)

Seizures (yes/no)

Ventilator dependence (days)

Postoperative hospital stay (days) 